\title{
Clinical Profiles and Complete Blood Count Could Not Identify Children Aged 3 to 36 Months Who Had Fever Without Source at High Risk for Bacteremia
}

\author{
Kanchanok Saraban, M.D., Kamolwish Laoprasopwattana, M.D. \\ Department of Pediatrics, Faculty of Medicine, Prince of Songkla University, Hat Yai, Songkhla 90110, Thailand. \\ Received 21 September 2020 • Revised 8 April $2021 \bullet$ Accepted 21 April $2021 \bullet$ Published online 16 June 2021
}

\begin{abstract}
:
Objectives: To evaluate the incidence and causes of occult bacteremia and whether clinical profiles and complete blood count could reliably identify high-risk-for-bacteremia children aged 3 to 36 months who had fever without source (FWS).

Material and Methods: The medical data of children aged 3 to 36 months who presented with FWS for 1 to 7 days but with no clinical signs of sepsis and were subsequently hospitalized between January 2007 and December 2017 with one or more of the following high risk features, body temperature $\geq 39$ degrees Celsius, inactive behavior, white blood cell (WBC) count $\geq 15,000$ cells per cubic millimeter (cells $/ \mathrm{mm}^{3}$ ), absolute neutrophil count $\geq 10,000$ cells $/ \mathrm{mm}^{3}$, or absolute band count $\geq 1,500$ cells $/ \mathrm{mm}^{3}$, were recorded.
\end{abstract}

Results: Bacteremia was found in 12 of 160 (7.5\%) children with one or more of the high-risk features. The pathogens were non-typhoidal Salmonella (5 patients), Streptococcus pneumoniae (4 patients), and Salmonella Typhi (3 patients). None of the high-risk features could differentiate between children with and without bacteremia. Five of the 8 patients with Salmonella septicemia had normal WBC counts leading to delays in prescribing empirical antibiotics and none of them had complications. None of the 117 patients in the non-bacteremia group who did not receive antibiotics or discontinued them after negative hemoculture had complications during hospitalization.

Conclusion: High-risk features could not help to identify occult bacteremia in children aged 3-36 months who had FWS.

Keywords: children aged 3 to 36 months, fever without localizing signs, occult bacteremia

Contact: Assoc. Prof. Kamolwish Laoprasopwattana, M.D.

Department of Pediatrics, Faculty of Medicine,

Prince of Songkla University, Hat Yai, Songkhla 90110, Thailand.

E-mail: kamolwish@gmail.com, Ikamolwi@medicine.psu.ac.th

This is an open access article under the CC BY-NC-ND license

(http://www.jhsmr.org/index.php/jhsmr/about/editorialPolicies\#openAccessPolicy).

J Health Sci Med Res 2022;40(2):129-136 doi: $10.31584 / j h s m r .2021819$ www.jhsmr.org 


\section{Introduction}

Acute fever without source (FWS) is a common problem in daily pediatric practice. Most of these FWS patients have self-limited viral infections which resolve with minimal treatment and no significant sequelae, but some of these largely asymptomatic patients may have occult bacteremia or be developing a serious bacterial infection, and in such children appropriate treatment is necessary to prevent a serious infection such as meningitis or sepsis.

Before routine immunization in western countries with pneumococcal conjugate vaccine (PCV) and Haemophilus influenzae type B (Hib) vaccine, the prevalence of occult bacteremia in well-appearing children aged 3 to 36 months who presented with FWS was 3.0-8.0\%. ${ }^{1,2}$ The predominant organisms were Streptococcus pneumoniae and Hib. In Southeast Asia, the prevalence of occult bacteremia was similar at $3.0-4.0 \%$ in the pre-PCV and Hib vaccines era, however, the common pathogens were different, as Salmonella spp was the most common cause while $S$ pneumoniae and $H$ influenzae were less commonly found as in other developing countries. ${ }^{3}$

Currently the PCV and Hib vaccines are given to children in developed countries, which has led to a decreased incidence of $S$ pneumonia and $H$ influenzae bacteremia from $5.0 \%$ to $<1.0 \%{ }^{4,5}$ In Thailand, however, only a small number of children receive these vaccines.

Various combinations of existing tests have been used in recent years to help identify a febrile child with a serious illness, along with diagnostic tests to quantify the risk of bacteremia and its complications, including white blood cell (WBC) and differential counts, microscopic examination of the buffy coat of blood, and morphologic changes in peripheral blood neutrophils. None of these tests, however, have sufficient sensitivity or positive or negative predictive values to identify an individual patient at risk $^{6}$, and thus antibiotics are frequently prescribed to be safe in patients who do not need them, increasing the general risk of antibiotic resistance. Antibiotics given only to patients at high risk for bacteremia would decrease the overuse of antibiotics and also prevent serious complications, such as meningitis, arthritis, and pneumonia, in patients who truly had bacteremia. ${ }^{7,8}$

In this study we wanted to examine the incidence and causes of occult bacteremia and also examine whether clinical profiles and complete blood counts (CBCs) can be used to identify Thai children at risk for occult bacteremia.

\section{Material and Methods}

The medical data of previously healthy children aged 3 to 36 months who presented with FWS for 1 to 7 days with no clinical signs of sepsis and at least one hemoculture result, and were at high-risk of having occult bacteremia as indicated by having at least one of the risk factors of inactive appearance, body temperature $\geq 39$ degrees Celsius, WBCs $\geq 15,000$ cells per cubic millimeter (cells $/ \mathrm{mm}^{3}$ ), absolute neutrophil count $(\mathrm{ANC}) \geq 10,000$ cells $/ \mathrm{mm}^{3}$, and/or absolute band count $(A B C) \geq 1,500$ cells $/ \mathrm{mm}^{3}$ and were subsequently hospitalized between January 2007 and December 2017 were recorded. ${ }^{6}$ Patients were excluded if (1) they had a known viral infection (eg, measles, croup, varicella) or focal bacterial infection (eg, cellulitis, otitis media, urinary tract infection, meningitis), (2) they had been previously treated with antibiotics (oral or intravenous) prior to blood and urine cultures, and/or (3) they were immunocompromised or had any chronic illness that would affect the approach to a febrile illness.

Children suspicious of having occult bacteremia who had mild upper respiratory tract infection (URI) and/or mild non-mucous acute gastroenteritis (AGE) (as diagnosed by $\leq 5$ times of watery stools, and without signs of moderate or severe dehydration) were not excluded from the study because mild URI and/or mild AGE are commonly found in children with acute illness regardless of local infection. 9,10 
Categorical variables were analyzed using the Pearson Chi-square test or Fisher's exact test and are presented as frequency and percentage. Non-parametric continuous data were analyzed using Mann-Whitney $U$ test and are presented as median and interquartile range. All $p$-values were two-tailed and a $p$-value $<0.050$ was deemed to indicate statistical significance.

This study was approved by the Human Research Ethic Committee of the Faculty of Medicine, Prince of Songkla University (REC. 61-076-1-4).

\section{Results}

Clinical characteristics and complete blood counts

During the 11-year study period, 160 children aged 3 to 36 months presented with FWS with one or more of the high-risk-for-bacteremia features. Positive hemocultures were found in 12 cases (7.5\%), the specific organisms being Salmonella spp (8 cases) and $S$ pneumoniae (4 cases). Of the 8 cases with Salmonella bacteremia, 5 and 3 cases were non-typhoidal Salmonella (NTS) and Salmonella Typhi, respectively.

Looking at only the 124 febrile children without AGE, occult bacteremia was found in 5/124 (4.0\%) patients, with the specific organisms being $S$ pneumoniae (4 cases) and Salmonella Typhi (1 case).

The baseline characteristics including age, gender, underlying diseases, malnutrition status (wasting and/or stunting), PCV and Hib vaccine status, and duration of fever prior to hospitalization were not statistically significantly different between the 2 groups (bacteremia and no bacteremia) (Table 1).

In the bacteremia group, an underlying disease was found in 1 case $(8.3 \%)$ compared to 9 cases $(6.1 \%)$ in the no bacteremia group. The patient with NTS had hemoglobin $\mathrm{H}$ disease. The underlying diseases of the other 9 cases in the no bacteremia group were Southeast Asian ovalocytosis
(2 cases) and one each of allergic rhinitis, cow's milk protein allergy, congenital hydronephrosis, bilateral vesicoureteral reflux grade II, facial hemihypertrophy, epilepsy, and pancreatic pseudocyst.

PCV and Hib immunization data were available in 66 and 67 cases in the bacteremia and no bacteremia groups, respectively. None of the 12 with completed PCV and none of the 33 cases with completed Hib by age had $S$ pneumococcus or $H$ influenzae bacteremia, respectively. None of the 4 patients with $S$ pneumonia bacteremia had had their PCV vaccinations.

The proportions of cases with upper respiratory tract symptoms (cough and/or runny nose) and/or vomiting were not statistically different between the 2 groups.

The proportion of cases with mild non-mucous bloody diarrhea was significantly higher in the positive hemoculture group than in the negative hemoculture group (58.3\% vs. $19.6 \%$, respectively, $p$-value $=0.002)$ and all 7 cases with non-mucous bloody diarrhea had Salmonella septicemia (Table 1).

Dehydration status, including decreased urine output and poor oral intake, and physical examination features including general appearance and maximum temperature, were also not different between the 2 groups. The total WBC counts, ANCs, and proportion of children with ANC $\geq 10,000$ cells $/ \mathrm{mm}^{3}$ were significantly lower in the bacteremia group (Table 1).

\section{High-risk features of occult bacteremia}

The proportions of children with one or more high-risk features for occult bacteremia including inactive behavior, body temperature $\geq 39^{\circ} \mathrm{C}$, and $\mathrm{ABC} \geq 1,500$ cells/ $\mathrm{mm}^{3}$ were not significantly different between the 2 groups. The proportion of children with $\mathrm{ANC} \geq 10,000$ cells $/ \mathrm{mm}^{3}$ was significantly lower in the positive hemoculture group (Table 1). 
Table 1 Comparing the characteristics of children with or without bacteremia

\begin{tabular}{|c|c|c|c|}
\hline Characteristic & $\begin{array}{l}\text { Bacteremia } \\
(n=12)\end{array}$ & $\begin{array}{l}\text { No bacteremia } \\
(n=148)\end{array}$ & p-value \\
\hline Age, months, median (IQR) & $12.0(10.0,31.9)$ & $14.5(9.4,25.6)$ & 0.950 \\
\hline Male, n (\%) & $7(58.3)$ & $80(54.1)$ & 0.770 \\
\hline Underlying disease, $\mathrm{n}(\%)$ & $1(8.3)$ & $9(6.1)$ & 0.550 \\
\hline \multicolumn{4}{|l|}{ Malnutrition status, n (\%) } \\
\hline Underweight* & $1(8.3)$ & $11(7.4)$ & $>0.999$ \\
\hline Stunting* & $0(0.0)$ & $5(3.4)$ & $>0.999$ \\
\hline Complete PCV by age, $\mathrm{n}(\%)$ & $1(16.7), \mathrm{n}=6$ & $11(18.3), n=60$ & 0.890 \\
\hline Complete Hib vaccine by age, $\mathrm{n}(\%)$ & $2(33.3), n=6$ & $31(50.8), n=61$ & 0.540 \\
\hline Duration of fever prior to hospitalization, days, median (IQR) & $3.5(2.2,6.0)$ & $2.0(1.0,3.0)$ & 0.002 \\
\hline \multicolumn{4}{|l|}{ Clinical symptoms, $\mathrm{n}(\%)$} \\
\hline Upper respiratory tract infection & $6(50.0)$ & $74(50.0)$ & $>0.999$ \\
\hline Vomiting & $3(25.0)$ & $46(31.1)$ & 0.757 \\
\hline Decreased urine output & $1(8.3)$ & $5(3.4)$ & 0.378 \\
\hline Poor oral intake & $6(50.0)$ & $84(56.8)$ & 0.650 \\
\hline Mild non-mucous bloody diarrhea & $7(58.3)$ & $29(19.6)$ & 0.002 \\
\hline Inactive appearance & $2(16.7)$ & $6(4.1)$ & 0.112 \\
\hline Maximum temperature, ${ }^{\circ} \mathrm{C}$, median $(\mathrm{IQR})$ & $40.0(38.9,40.7)$ & $39.3(39.0,40.0)$ & 0.100 \\
\hline Body temperature $\geq 39^{\circ} \mathrm{C}, \mathrm{n}(\%)$ & $9(75.0)$ & $120(81.1)$ & 0.703 \\
\hline \multicolumn{4}{|l|}{ Complete blood count findings } \\
\hline WBCs, $\times 10^{3}$ cells $/ \mathrm{mm}^{3}$, median (IQR) & $15.5(6.5,21.5)$ & $20.0(15.8,26.0)$ & 0.040 \\
\hline WBCs $\geq 15 \times 10^{3}$ cells $/ \mathrm{mm}^{3}, \mathrm{n}(\%)$ & $7(58.3)$ & $121(81.8)$ & 0.051 \\
\hline ANCs, $\times 10^{3}$ cells $/ \mathrm{mm}^{3}$, median (IQR) & $6.5(3.4,13.8)$ & $12.4(8.9,16.8)$ & 0.030 \\
\hline ANCs $\geq 10 \times 10^{3}$ cells $/ \mathrm{mm}^{3}, \mathrm{n}(\%)$ & $4(33.3)$ & $143(66.2)$ & 0.030 \\
\hline ABCs, cells $/ \mathrm{mm}^{3}$, median (IQR) & $126.0(0.0,822.0)$ & $309.0(0.0,935.0)$ & 0.693 \\
\hline $\mathrm{ABCs} \geq 1500 \mathrm{cells} / \mathrm{mm}^{3}, \mathrm{n}(\%)$ & $2(16.7)$ & $21(14.7)$ & 0.693 \\
\hline Haemoglobin, g/dL, median (IQR) & $11.1(10.0,12.3)$ & $11.5(10.6,12.1)$ & 0.410 \\
\hline Platelets, $\times 10^{3}$ cells $/ \mathrm{mm}^{3}$, median (IQR) & $315.0(241.0,378.0)$ & $362.0(303.0,436.0)$ & 0.171 \\
\hline
\end{tabular}

*Underweight: weight lower than $2^{\text {nd }}$ standard deviation (S.D.) of normal body weight for age; Stunting, patient height lower than $2^{\text {nd }}$ S.D. of normal length for age

IQR=interquartile range, PCV=pneumococcal conjugate vaccine, Hib=Haemophilus influenzae type $\mathrm{B}, \mathrm{WBC}=$ white blood cell, ANC=absolute neutrophil count, $\mathrm{ABC}=$ absolute band count

\section{Comparing the profiles of salmonella and other}

\section{bacteremia}

Of the 12 cases with bacteremia, 8 and 4 cases had Salmonella and pneumococcal bacteremia, respectively. Non-mucous bloody diarrhea was found in $7 / 8$ cases of Salmonella bacteremia but none of the pneumococcal bacteremia cases. WBCs $\geq 15,000$ cells $/ \mathrm{mm}^{3}$ and/or $\mathrm{ABC}$ $\geq 1,500$ cells $/ \mathrm{mm}^{3}$ were found in $4 / 8(50.0 \%)$ children with Salmonella bacteremia and 4/4 (100\%) children with pneumococcal bacteremia (Table 2).
Of the total 8 cases with Salmonella bacteremia, all 5 cases with NTS were less than 2 years of age (range 5.8-12.5 months) and all 3 cases with typhoid fever were older than 2 years (range 32-34 months).

Of the 7 cases with non-mucous bloody diarrhea, only 4 cases had stool examination results, with stool WBCs in 3 cases and rectal cultures which revealed non-typhoidal Salmonella in 2 cases. 


\section{Treatment and outcomes}

Of the 12 cases with positive hemoculture, 5 cases $(41.7 \%)$ received empirical antibiotics within 24 hours and 7 cases (Salmonella (6) and S pneumoniae (1)) were treated after the hemoculture report (Table 3). No serious bacterial complications occurred in those who received antibiotics after 24 hours.

Of the 11 and 1 cases that were treated with ceftriaxone and ampicillin, respectively, all of the pathogens isolated were susceptible to the given antibiotics.

Of the 148 cases with negative hemoculture, 124 (83.8\%) received antibiotics. Of the 95 cases who dis- continued antibiotics after hemoculture reported negative and the 24 cases who did not receive antibiotics, none had complications or developed septic symptoms during prior to hospital discharge.

Comparing the cases with and without positive hemoculture, the median duration of antibiotics (10.5 vs. 2 days, respectively) and total duration of fever (7 vs. 3 days, respectively) were significantly longer in the positive hemoculture group than in the negative hemoculture group (Table 3).

Table 2 Comparison between salmonella bacteremia and pneumococcal bacteremia

\begin{tabular}{llll}
\hline Profiles & $\begin{array}{l}\text { Salmonella spp } \\
(\mathbf{n = 8})\end{array}$ & $\begin{array}{c}\text { S pneumoniae } \\
(\mathbf{n}=4)\end{array}$ & p-value \\
\hline Age, month, median (IQR) & $12.0(7.2,32.8)$ & $11.9(10.1,26.2)$ & 0.541 \\
Vomiting & $2(25.0)$ & $1(25.0)$ & $>0.999$ \\
Non-mucous bloody diarrhea & $7(87.5)$ & $0(0.0)$ & 0.010 \\
Body temperature $\geq 39{ }^{\circ} \mathrm{C}, \mathrm{n}(\%)$ & $5(62.5)$ & $4(100)$ & 0.491 \\
WBCs $\geq 15 \times 10^{3} \mathrm{cell} s / \mathrm{mm}^{3}, \mathrm{n}(\%)$ & $3(37.5)$ & $4(100)$ & 0.081 \\
ANC $\geq 10 \times 10^{3} \mathrm{cells} / \mathrm{mm}^{3}, \mathrm{n}(\%)$ & $0(0.0)$ & $4(100)$ & 0.002 \\
ABC $\geq 1500$ cells $/ \mathrm{mm}^{3}, \mathrm{n}(\%)$ & $2(25.0)$ & $0(0.0)$ & 0.515 \\
Duration of fever prior to hospitalization, days, median (IQR) & $5.0(3.0,6.8)$ & $2.0(0.5,3.5)$ & 0.030 \\
Duration of fever prior to intravenous antibiotic, days, median (IQR) & $6.0(4.5,6.8)$ & $2.0(0.5,3.5)$ & 0.002 \\
Duration of fever, days, median (IQR) & $7.5(7.0,8.8)$ & $3.0(2.2,6.0)$ & 0.010 \\
\hline
\end{tabular}

IQR=interquartile range, $\mathrm{WBC}=$ white blood cell, $\mathrm{ANC}=$ absolute neutrophil count, $\mathrm{ABC}=$ absolute band count

Table 3 Comparing the management and outcomes of children aged 3-36 months with or without bacteremia

\begin{tabular}{llll}
\hline Variable & $\begin{array}{l}\text { Bacteremia } \\
(\mathbf{n}=12)\end{array}$ & $\begin{array}{l}\text { No bacteremia } \\
(\mathbf{n}=148)\end{array}$ & $\mathbf{p}$-value \\
\hline Day IV antibiotic started, $\mathrm{n}(\%)$ & & & 0.001 \\
Day 0-1 & $5(41.7)$ & $101 / 124(81.5)$ & \\
Day 2-3 & $7(58.3)$ & $23 / 124(18.5)$ & \\
Duration of antibiotic, days, median (IQR) & $10.5(9.0,13.0)$ & $2.0(1.0,4.0),(\mathrm{n}=124)$ & $<0.001$ \\
Total duration of fever, days, median (IQR) & $7.0(3.7,8.0)$ & $3.0(2.0,4.0)$ & $<0.001$ \\
\hline
\end{tabular}

$I V=$ intravenous, IQR=interquartile range 


\section{Discussion}

We found that the incidence of occult bacteremia in FWS children aged 3-36 months was 7.5\% if including children with mild AGE and $4.0 \%$ if excluding those with mild AGE. The common pathogens were Salmonella spp and $S$ pneumoniae, and none of the high-risk criteria could help to differentiate between those with or without bacteremia.

Previous studies done in developed countries from the pre-conjugate-vaccine era found rates of occult bacteremia in children 3-36 months of age with fever $\geq 39^{\circ} \mathrm{C}$ of around $3.0 \%$. ${ }^{11,12}$ Studies done in Southeast Asia by Brooks et al., $2007^{13}$ and Leelarasamee et al., $2004^{14}$ found incidences of occult bacteremia of $3.0-4.0 \%$, similar to our study.

Diagnosis and management of febrile children 3 to 36 months of age with FWS in our institute follows the Baraff et al. guidelines. ${ }^{6}$ Generally a child with WBCs $\geq 15,000$ cells $/ \mathrm{mm}^{3}$ will have a blood culture done and be treated with ceftriaxone pending the culture results. ${ }^{6}$

Our study found as in previous studies that less than $50.0 \%$ of all Salmonella spp bacteremia cases had WBCs $\geq 15,000$, ANC $\geq 10,000$ and/or $A B C \geq 1,500$ cells/ $\mathrm{mm}^{3}$, which shows the limitation of using high-risk factors for occult bacteremia as an indication for empirical antibiotic administration in our group of Thai children. ${ }^{15-17}$ Our results were similar to previous studies ${ }^{4,6,18-20}$ which also concluded that it is difficult to identify children for whom empirical antibiotics should be given., 51,22

We found that the total WBC counts, ANCs, and proportion of children with $\mathrm{ANC} \geq 10,000$ cells $/ \mathrm{mm}^{3}$ were significantly lower in the bacteremia group. This finding could be explained by noting that, firstly, we enrolled only children with high risk features of occult bacteremia in which $>80.0 \%$ of the no bacteremia group had WBC counts $\geq 15,000$ cells $/ \mathrm{mm}^{3}$, ANCs $\geq 10,000$ cells $/ \mathrm{mm}^{3}$, and/or ABCs $\geq 1,500$ cells $/ \mathrm{mm}^{3}$; secondly, Salmonella spp. was the major cause of bacteremia in these patients, an organism which does not cause leukocytosis.

We found as in previous studies that children with occult pneumococcal bacteremia had only a low risk of developing serious complications ${ }^{1,7}$, and also children with typhoid and NTS bacteremia secondary to NTS enteritis had a good prognosis even though they did not receive antibiotics until after hemoculture reports, with a median duration of fever prior to intravenous antibiotics of 6 days. $^{23-25}$ We found that most patients with Salmonella spp bacteremia were initially diagnosed as acute viral gastroenteritis, which could be explained by noting the long median duration of fever prior to antibiotic administration. We suggest that young children who are initially diagnosed with viral AGE or other acute febrile illness should have hemocultures done if they have fever $\geq 5$ days and have no clinical symptoms that indicate an identifiable cause of fever because the duration of fever in children with viral infection is usually less than 5 days. ${ }^{10,26,27}$

Although $H$ influenzae and $N$ meningitides are known to cause more complications than $S$ pneumoniae, ${ }^{7}$ these organisms were not found in our study. This could be explained by the fact that we included children aged 3-36 months who were previously healthy with no clinical signs of sepsis while the majority of children with $H$ influenzae and $N$ meningitides bacteremia would have signs of clinical sepsis.

A previous study found that $S$ Typhi was most commonly found in school age children; ${ }^{28}$ in our study all 3 patients with $S$ Typhi were aged 32-34 months and all 5 cases with NTS were aged less than 13 months. The different age groups affected by these 2 diseases could be explained by noting that NTS is more likely to infect an immunocompromised host, unlike $S$ Typhi which can infect anyone regardless of their immune status, and older children have a higher chance of being exposed to $S$ Typhi than younger children. 
In our study, although $85.0 \%$ of the cases received an antibiotic unnecessarily due to a negative hemoculture, the antibiotics were discontinued after the negative hemoculture was returned without any complications during hospitalization. However, with the limitation of a retrospective study of not having follow up data after hospital discharge, we could not be certain whether or not these febrile children had any later complications.

Taking these findings together suggests that wellappearing children aged 3 to 36 months who have FWS, but have had their PCV and Hib vaccinations and have a normal urinalysis, can be closely observed with no need for hemoculture. Previous studies found that contaminants isolated from hemocultures were 10-20 times more often found than pathogens and WBC counts were not a useful way to assess the risk of occult bacteremia in children aged more than 90 days. ${ }^{5,21,22}$ However, in cases in which fever persists $\geq 5$ days, a hemoculture should be done regardless of $\mathrm{CBC}$ results to exclude occult bacteremia. In addition, if a patient has not had their PCV and Hib vaccinations, a hemoculture should be performed, but with no need for an initial empirical antibiotic. This can reduce the excessive use of antibiotics without any harmful consequences. However, further large prospective cohort studies are needed to confirm this suggestive guideline in developing countries.

The main limitation of this study was a possible selection bias, in that hemocultures were only performed if the attending clinician felt it was necessary, and thus some of the patients with high-risk features but clinically suspected of a viral infection may not have had a hemoculture performed and were thus not included in the study. The other notable limitation was the retrospective nature of the study, which means some data may have been missed, and thus some variables not accurately assessed. Prospective multicenter studies with larger sample sizes for generalizability and more comprehensive results are needed.

\section{Acknowledgement}

The authors wish to thank David Patterson, an English teacher and consultant with the Faculty of Medicine, Prince of Songkla University, for help with the English.

\section{Conflict of interest}

This work had no financial or commercial conflicts of interest.

\section{References}

1. McGowan JE Jr., Bratton L, Klein JO, Finland M. Bacteremia in febrile children seen in a "walk-in" pediatric clinic. N Engl $J$ Med 1973;288:1309-12.

2. Teele DW, Pelton SI, Grant MJ, Herskowitz J, Rosen DJ, Allen CE,et al. Bacteremia in febrile children under 2 years of age: results of cultures of blood of 600 consecutive febrile children seen in a "walk-in" clinic. J Pediatr 1975;87:227-30.

3. Deen J, von Seidlein L, Andersen F, Elle N, White NJ, Lubell Y. Community-acquired bacterial bloodstream infections in developing countries in south and southeast Asia: a systematic review. Lancet Infect Dis 2012;12:480-7.

4. Stoll ML, Rubin LG. Incidence of occult bacteremia among highly febrile young children in the era of the pneumococcal conjugate vaccine: a study from a Children's Hospital Emergency Department and Urgent Care Center. Arch Pediatr Adolesc Med 2004;158:671-5.

5. Bressan S, Berlese P, Mion T, Masiero S, Cavallaro A, Da Dalt L. Bacteremia in feverish children presenting to the emergency department: a retrospective study and literature review. Acta Paediatr 2012;101:271-7.

6. Baraff LJ, Bass JW, Fleisher GR, Klein JO, McCracken GH Jr, Powell KR. Practice guideline for the management of infants and children 0 to 36 months of age with fever without source. Agency for Health Care Policy and Research. Ann Emerg Med 1993;22:1198-210.

7. Shapiro ED, Aaron NH, Wald ER, Chiponis D. Risk factors for development of bacterial meningitis among children with occult bacteremia. J Pediatr 1986;109:15-9.

8. Baraff LJ, Oslund S, Prather M. Effect of antibiotic therapy and etiologic microorganism on the risk of bacterial meningitis in children with occult bacteremia. Pediatrics 1993;92:140-3. 
9. Laoprasopwattana K, Limpitikul W, Geater A. Using clinical profiles and complete blood counts to differentiate causes of acute febrile illness during the 2009-11 outbreak of typhoid and chikungunya in a dengue endemic area. $J$ Trop Pediatr 2020;66:504-10.

10. Streng A, Prifert C, Weissbrich B, Schmidt-Ott R, Liese JG. Subtype-specific clinical presentation, medical treatment and family impact of influenza in children 1-5 years of age treated in outpatient practices in Germany during three postpandemic years, 2013-2015. Pediatr Infect Dis J 2018; 37:861-7.

11. Fleisher GR, Rosenberg N, Vinci R, Steinberg J, Powell K, Christy C, et al. Intramuscular versus oral antibiotic therapy for the prevention of meningitis and other bacterial sequelae in young, febrile children at risk for occult bacteremia. J Pediatr 1994;124:504-12.

12. Jaffe DM, Tanz RR, Davis AT, Henretig F, Fleisher G. Antibiotic administration to treat possible occult bacteremia in febrile children. N Engl J Med 1987;317:1175-80.

13. Brooks WA, Breiman RF, Goswami D, Hossain A, Alam K, Saha $S K$, et al. Invasive pneumococcal disease burden and implications for vaccine policy in urban Bangladesh. Am J Trop Med Hyg 2007;77:795-801.

14. Leelarasamee A, Chupaprawan C, Chenchittikul M, Udompanthurat $\mathrm{S}$. Etiologies of acute undifferentiated febrile illness in Thailand. J Med Assoc Thai 2004;87:464-72.

15. Whistler T, Sapchookul P, McCormick DW, Sangwichian O, Jorakate $\mathrm{P}$, Makprasert $\mathrm{S}$, et al. Epidemiology and antimicrobial resistance of invasive non-typhoidal Salmonellosis in rural Thailand from 2006-2014. PLoS Negl Trop Dis 2018; 12:e0006718.

16. Tsai MH, Huang YC, Chiu CH, Yen MH, Chang LY, Lin PY, et al. Nontyphoidal Salmonella bacteremia in previously healthy children: analysis of 199 episodes. Pediatr Infect Dis J 2007;26:909-13.

17. Punpanich W, Netsawang S, Thippated C. Invasive salmonellosis in urban Thai children: a ten-year review. Pediatr Infect Dis J 2012;31:e105-10.

18. Sard B, Bailey MC, Vinci R. An analysis of pediatric blood cultures in the postpneumococcal conjugate vaccine era in a community hospital emergency department. Pediatr Emerg Care 2006;22:295-300.
19. Herz AM, Greenhow TL, Alcantara J, Hansen J, Baxter RP, Black SB, et al. Changing epidemiology of outpatient bacteremia in 3- to 36-month-old children after the introduction of the heptavalent-conjugated pneumococcal vaccine. Pediatr Infect Dis J 2006;25:293-300.

20. Benito-Fernandez J, Mintegi S, Pocheville-Gurutzeta I, Sánchez Etxaniz J, Gómez Cortés B, Hernández Almaraz JL. Pneumococcal bacteremia in febrile infants presenting to the emergency department 8 years after the introduction of pneumococcal conjugate vaccine in the Basque Country of Spain. Pediatr Infect Dis J 2010; 29:1142-4.

21. Waddle E, Jhaveri R. Outcomes of febrile children without localising signs after pneumococcal conjugate vaccine. Arch Dis Child 2009;94:144-7.

22. Jhaveri R, Byington CL, Klein JO, Shapiro ED. Management of the non-toxic-appearing acutely febrile child: a $21^{\text {st }}$ century approach. J Pediatr 2011;159:181-5.

23. Yang YJ, Huang MC, Wang SM, Wu JJ, Cheng CP, Liu CC. Analysis of risk factors for bacteremia in children with nontyphoidal Salmonella gastroenteritis. Eur J Clin Microbiol Infect Dis 2002;21:290-3.

24. Hung TY, Liu MC, Hsu CF, Lin YC. Rotavirus infection increases the risk of bacteremia in children with nontyphoid Salmonella gastroenteritis. Eur J Clin Microbiol Infect Dis 2009;28:425-8.

25. Tsai KS, Yang YJ, Wang SM, Chiou CS, Liu CC. Change of serotype pattern of Group D non-typhoidal Salmonella isolated from pediatric patients in southern Taiwan. J Microbiol Immunol Infect 2007;40:234-9.

26. Crawford SE, Ramani S, Tate JE, Parashar UD, Svensson L, Hagbom M, et al. Rotavirus infection. Nat Rev Dis Primers 2017;3:17083.

27. Laoprasopwattana K, Kaewjungwad L, Jarumanokul R, Geater A. Differential diagnosis of Chikungunya, dengue viral infection and other acute febrile illnesses in children. Pediatr Infect Dis J 2012;31:459-63.

28. Limpitikul W, Henpraserttae N, Saksawad R, Laoprasopwattana K. Typhoid outbreak in Songkhla, Thailand 2009-2011: clinical outcomes, susceptibility patterns, and reliability of serology tests. PLoS One 2014;9:e111768. 